\title{
Una grieta de doscientos años. Conflictos y debates constituyentes en la Argentina (1816-1827)
}

\author{
Julio Saguir
}

Buenos Aires: Prometeo Libros, 2020. 385 páginas.

\section{Sebastián G. Cortesi}

\section{DOI: https://doi.org/10.46468/rsaap.14.1.R5}

El proceso de organización nacional está plagado de constituciones fallidas. Julio Saguir ha consagrado su trayectoria como investigador a explicar este atolladero institucional a partir de las herramientas provistas por el análisis estratégico. En esta ocasión, el autor extiende su diálogo intelectual con Adam Przeworski, Jon Elster y Bernard Manin a los Congresos Constituyentes (unitarios) de 1816-1819 y 1824-1827. El lector es invitado a adoptar el punto de vista de los actores. ¿Por qué las provincias rechazaron ambos textos? ¿Pueden redactarse constituciones exitosas en contextos atravesados por el conflicto? Son las preguntas que estructuran el análisis de las posiciones y los argumentos vertidos durante los debates constituyentes.

Si bien se trata de un trabajo de análisis político, es necesario reconocer que el libro sintoniza con las percepciones del estado del arte historiográfico. Lejos de ser eclipsado por una "fórmula operativa", el diseño institucional reviste una importancia fundamental. Los debates constituyentes no son parroquiales ni se inscriben dentro de una trama teleológica; por el contrario, son objetos contingentes signados por una complejidad asimilable a la de la Convención de Filadelfia.

La obra se divide en dos secciones. Saguir dedica los tres primeros capítulos a someter el objeto a las categorías del rational choice institutionalism. El autor muestra que los congresales se reunieron para producir un bien colectivo e instrumental: una constitución capaz de organizar una unidad política nacional libre de los fantasmas del despotismo. La experiencia del gobierno republicano enseñó a los constituyentes que el despotismo puede ser una relación vertical entre gobernantes y gobernados, o bien horizontal en términos de un poder omnímodo o, más preocupante aún, una provincia hegemónica. Para exorcizar dichos fantasmas, los actores coinciden con Montesquieu en la necesidad de un régimen mixto.

Este es el punto de partida de un dilema del prisionero. El problema, señala Saguir, reside en que ningún modelo normativo es capaz de producir un equilibrio institucional. La gama de opciones disponibles, desde el federalismo descentralizado hasta el unitarismo acérrimo, no puede organizar satisfactoriamente los intereses contrapuestos de las provincias. Para elevar aún más la dificultad del juego, Saguir echa luz sobre la asimetría entre los actores y la naturaleza de sus preferencias. Buenos Aires es el único jugador capaz de costear la solución constitucional, mas solamente se dispondrá a hacerlo bajo una modalidad centralista. Las provincias, especialmente Córdoba, Mendoza y Santa Fe, estiman que el costo de la hegemonía bonaerense supera los beneficios de la unión. Como consecuencia, estas acaban adoptando soluciones 
subóptimas -secesión provincial o regional-con la esperanza de reiniciar el juego.

Planteado el tablero, la segunda mitad del libro pone el juego en funcionamiento. Los capítulos 4 y 5 ilustran la dinámica de la interacción estratégica a partir del análisis de los argumentos y los dispositivos institucionales vinculados a la representación nacional. El autor sugiere que los constituyentes concibieron al Senado como la piedra angular del equilibrio institucional. De inspiración burkeana, la cámara alta debía discernir el bien común a partir de la deliberación de los intereses provinciales y, además, estaba llamada a acoger a los más conspicuos representantes de los intereses económicos. No obstante, Saguir no ofrece una descripción parcial de la racionalidad constituyente. Además de un "principio de distinción", los congresales percibieron la necesidad de una cámara baja democrática y dieron por tierra con el legado colonial de representación por fueros (eclesiástico, militar y universitario).

A continuación, el autor propone dos perspectivas analíticas que merecen ser destacadas. Por un lado, Saguir incurre en una comparación permanente entre ambas asambleas a los efectos de demostrarle al lector que se encuentra ante un juego de repetición. Es decir, el arreglo institucional 1824-1827 no puede comprenderse sin considerar cómo los actores evaluaron los escollos que condujeron a Cepeda. Adicionalmente, la comparación permite distinguir dos niveles dentro del juego: el diseño normativo y la estrategia de implementación del mismo. Nuevamente, el constituyente recoge los beneficios de la experiencia. Los actores de la década del veinte insistieron en una propuesta unitaria (atenuada por concesiones políticas y fiscales) convencidos de que una estrategia de "unidad por convención" resolvería el juego. Inspirados en el ejemplo de Rhode Island, la facción centralista especuló con que, en el mediano plazo, las provincias díscolas finalmente comprenderían que los beneficios de la unión superaban con creces los costos de la secesión. Hasta entonces, la prioridad de la política nacional consistía en organizar el Estado para así acelerar la materialización de los beneficios colectivos.

El capítulo final recoge los frutos que el autor ha sembrado con solvencia a lo largo de la obra. Una vez analizado el desenlace de ambos juegos, Saguir despliega su hipótesis principal. El primer intento constituyente se dio en el marco de un sistema centralizado de organización política de los pueblos (provincias), heredado del régimen virreinal. En cambio, el segundo ensayo tuvo lugar en una especie de estado de naturaleza donde las provincias gozaban de plena autonomía e independencia. A pesar de la notable diferencia entre ambos contextos políticoinstitucionales, ningún congreso logró consumar la unión. Difícilmente podría hallarse mejor material para aplicar el "diseño basado en los casos más diferentes". Saguir sostiene que la preferencia provincial por el autogobierno es el factor explicativo común. En otras palabras, el equilibro institucional únicamente puede materializarse bajo un ordenamiento federal.

Compártase o no la lectura, Saguir logra documentar que los actores conocían la estructura del conflicto y estaban al tanto de sus posibles soluciones; es decir, no había un problema de percepción. La sucesión de fracasos sugiere que el problema era intrínseco, que 


\section{Revista SAAP $\cdot$ Vol. 14, № 1}

los elencos constituyentes se hallaban inmersos en un juego imposible. Esta provocativa hipótesis explicaría por qué la unión argentina (1853-1860) fue el resultado de las armas de Pavón y no un outcome racional.

Una grieta de doscientos años es un sugerente ejercicio de análisis político.
Los argumentos desplegados interesan a politólogos e historiadores por igual. La mixtura interdisciplinar de preguntas y perspectivas invitan a entablar un diálogo entre dichos argumentos y los estudios que versan sobre la construcción del Estado y el federalismo en la Argentina. 